\title{
平行板プラストメーターの理論*
}

岡 小 天** 小川七キ子**

\section{Theory of Parallel-Plate Plastometer}

by

\author{
Syoten OKa and Sekiko Ogawa \\ (Department of Physics, Tokyo Metropolitan University, Tokyo)
}

The parallel-plate plastometer is a simple and important instrument to investigate rheological behavior of matter. Especially, it is very useful for materials which have yield values. But there is only Scott's theory for this case and he made rather rough assumptions in the beginning of the calculation, so it is not sure whether the final result is reasonable or not. We have made calculation starting from the general equation of motion for the Bingham solid and obtained the relationship between the thickness of the specimen $h$ and the time $t$ when a constant force is applied perpendicular to the plates. Calculations have been made for the two cases: (a) The specimen is larger than the plates; thus the area under compression is constant. (b) The plates are larger than the specimen; thus the volume of the specimen is constant. Our final results (34) and (40) enable us to determine the yield value and the coefficient of plastic viscosity $\eta$. And our results reduces to the equations derived by Stefan and Healey when the yield value $f$ is neglected.

(Received Jan. 5, 1960)

\section{1.はしがき}

平行板プラストメーターは装置として簡単なもので あり，物体のレオロジカルな性質を調へるうえに重要 なものである。ニニートン液体に対しては Stefan お よひ Healey により簡単な公式が得られている. 近年 Dienes らは Navier-Stokes の式から出発してある近 似のもとに同じ結果を導いた．この計算は Stefan や Healey の公式がとのような条件のもとに成り立つか を明らかにしている点で重要である. 平行板プラスト メーターは高粘度の非ニュートン流動をする物体, と くに降伏点を有する物体に対して意味があるがここの 場合に対する理論としては Scott のがあるだけである. Scott の取扱いでは最初からかなりひとい近似を入れ ているので, 最後の結果がとの程度信頼てきるか明ら かでない.ここでは降伏点を示すもっとも簡単な物体 としてビンガム物体をとり，なるべく近似を入れすに

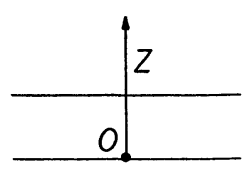

Fig. 1 Cylindrical coordinates

* 原稿受付 昭和35年 1 月 5 日

** 東京都立大学理学部物理学教室
計算を行なう方針をとった：ます，ビンガム物体に対 する一般運動方程式から出発して, 平板に一定の外力 が作用したとさの平板間距離 $h$ と時間との関係を導く. この関係式にパラメーターとして平板間にはさまれて いるビンガム物体の降伏值 $f$ と塑粘性率 $\eta$ とがはいる. (Fig. 1 参照)

\section{2. 基礎方程式}

まず，平行板プラストメーターの中心を座標の原点 に選び，板面に垂直に $z$ 軸をとり，丹筒座標 $(r, \theta, z)$ を用いることにする，そうすると降伏值 $f$, 塑粘性率 クなるビンガム物体が運動している場合, 応力ーひずみ の関係式を円筒座標を用いてテンソル形式で表わすと 一般につきのようになる，ただし物体は非圧縮性とす る. $p_{r r}, p_{\theta \theta}, p_{z z}, p_{\theta z}, p_{z}, p_{r \theta}$ は応力テンソルの成 分, $v_{r}, v_{\theta}, v_{z}$ は速度ベクトルの成分で, $p$ は静圧力 を意味する。

$$
\left.\begin{array}{l}
p_{r r}=-p+2 \eta \frac{\partial v_{r}}{\partial r} \\
p_{\theta \theta}=-p+2 \eta\left(\frac{1}{r} \frac{\partial v_{\theta}}{\partial \theta}+\frac{v_{r}}{r}\right) \\
p_{z z}=-p+2 \eta \frac{\partial v_{z}}{\partial z} \\
p_{\theta z}=\eta\left(\frac{1}{r} \frac{\partial v_{z}}{\partial \theta}+\frac{\partial v_{\theta}}{\partial z}\right)+f \\
p_{z r}=\eta\left(\frac{\partial v_{r}}{\partial z}+\frac{\partial v_{z}}{\partial r}\right)+f \\
p_{r_{\theta}}=\eta\left(\frac{\partial v_{\theta}}{\partial r}+\frac{1}{r} \frac{\partial v_{r}}{\partial \theta}-\frac{v_{\theta}}{r}\right)+f
\end{array}\right\}
$$


問題の性質から明らかなように, $v_{\theta}=0$ でかつ $v_{r}, v_{z}$ は $\theta$ にはよらない.したがって，いまの場合上式はつ きのように簡単になる。

$$
\begin{aligned}
& p_{r r}=-p+2 \eta \frac{\partial v_{r}}{\partial r} \\
& p_{\theta \theta}=-p+2 \eta \frac{v_{r}}{r} \\
& p_{z z}=-p+2 \eta \frac{\partial v_{z}}{\partial z} \\
& p_{\theta z}=f \\
& p_{z r}=\eta\left(\frac{\partial v_{\gamma}}{\partial z}+\frac{\partial v_{z}}{\partial r}\right)+f \\
& p_{r \theta}=f
\end{aligned}
$$

以下プラストメーターの板面距離が円板の半径に比べ て充分小さい場合に限る。このときには $\partial v_{r} / \partial r \approx 0$ と 考えるから，(2)により $p_{r r}=-p$ となる. Fig 2 に おいて斜線をつけた部分の力のつりあいを考えれば $z=0$ で $p_{z r}=0$ なることを考慮してつきの式が導かれ る.

$$
\begin{gathered}
(\operatorname{prd} \theta z)- \\
\left.+\operatorname{prd} \theta z+\frac{\partial}{\partial r}(\operatorname{prd} \theta z) d r\right\} \\
+p_{z r} r d \theta d r=0
\end{gathered}
$$

すなわち,ずれ応力 $p_{z r}$ はつぎのようになる.

$$
p_{z r}=\frac{z}{r} \frac{\partial}{\partial r}(p r)
$$

ところで(2)の $p_{z r}$ の式は， $z$ が正または負であるに したがってそれぞれつきのように書くべきものである.

$$
\left.\begin{array}{l}
p_{z r}=\eta\left(\frac{\partial v_{r}}{\partial z}+\frac{\partial v_{z}}{\partial r}\right)-f, z>0 \\
p_{z r}=\eta\left(\frac{\partial v_{r}}{\partial z}+\frac{\partial v_{z}}{\partial r}\right)+f, z<0
\end{array}\right\}
$$

いま， $z>0$ の場合を考える. $z$ が充分小さなところ では $p_{z r}$ の大きさは降伏值 $f$ に達せず, 相対速度は生 じないものと考えられる。相対速度の現われる最小の $z$ の值は $p_{z r}=-f$ で決められる.あるいは

$$
\frac{z}{r} \frac{\partial}{\partial r}(p r)=-f
$$

これから

$$
z=-\frac{f r}{\partial(p r) / \partial r}
$$

$f$ は定数であるから，ビンガム物体の流動している部 分に対しては Navier-Stokes の式をそのまま適用す ることができる。平行板プラストメーターでは速度は 充分小さく 2 乗の項は無視されるからつきのように簡 単になる.

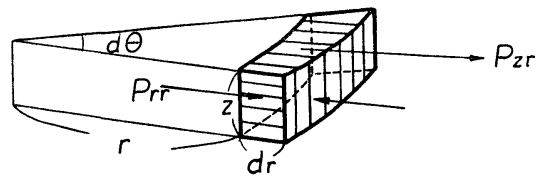

Fig. 2 Equilibrium of forces

$$
\left.\begin{array}{l}
\partial p / \partial r=\eta \nabla^{2} v_{r} \\
\frac{\partial p}{\partial z}=\eta \nabla^{2} v_{z}
\end{array}\right\}
$$

\section{3. 平行板プラストメーターの基礎方程式}

(8)の第 2 式から

$$
\frac{\partial p}{\partial z}=\eta \nabla^{2} v_{z}=\eta\left(\frac{\partial^{2} v_{z}}{\partial r^{2}}+\frac{1}{r} \frac{\partial v_{z}}{\partial r}+\frac{\partial^{2} v_{z}}{\partial z^{2}}\right)
$$

平行板距離が充分小さいとさ $v_{z}$ は小さく, (9)の右辺 はほとんど零に等しい.したがって， $p$ はには無関 係で $r$ と だけの関数とみなされる.ゆえに(8)の第 1 式は

$$
\frac{d p}{d r}=\eta\left(\frac{\partial^{2} v_{r}}{\partial r^{2}}+\frac{1}{r} \frac{\partial v_{r}}{\partial r}+\frac{\partial^{2} v_{r}}{\partial z^{2}}\right)
$$

となる。 $\partial v_{r} / \partial r$ は $\partial v_{r} / \partial z$ に対して無視できるから

$$
\frac{d p}{d r}=\eta \frac{\partial^{2} v_{r}}{\partial z^{2}}
$$

$z$ について積分して

$$
\frac{\partial v_{r}}{\partial z}=\frac{p^{\prime}}{\eta} z+c
$$

ただし $p^{\prime}$ は $d p / d r$ を意味する. Fig. 3 からわかる ように $\partial v_{r} / \partial z$ は $z=-f r /(p r)^{\prime}$ で零となる.このこ とから(12)における $c$ の值が定まり， $\partial v_{r} / \partial z$ はつぎ のようになる。

$$
\frac{\partial v_{r}}{\partial z}=\frac{p^{\prime}}{\eta} z+\frac{f r}{\eta} \frac{p^{\prime}}{(p r)^{\prime}}
$$

$z$ について積分すればただちに $v_{r}$ がつぎのように求 まる。

$$
v_{r}=\frac{p^{\prime}}{2 \eta} z^{2}+\frac{f r}{\eta} \frac{p^{\prime}}{(p r)^{\prime}} z+c^{\prime}
$$

板面ではビンガム物体と面との間に相対的なスリップ はないと考えるから， $v_{r}$ は $z=h / 2$ で零である。この ことから $c^{\prime}$ が定まり， $v_{r}$ は次式のようになる。

$$
v_{r}=\frac{p^{\prime}}{2 \eta}\left(z^{2}-\frac{h^{2}}{4}\right)+\frac{f r}{\eta} \frac{p^{\prime}}{(p r)^{\prime}}\left(z-\frac{h}{2}\right)
$$

つきに連続の式

$$
\frac{\partial}{\partial r}\left(r v_{r}\right)+\frac{\partial}{\partial z}\left(r v_{z}\right)=0
$$

より $h$ に関する式を導く.上式を $z$ につて $-h / 2$ か ら $h / 2$ まで，すなわち平行板間で積分すれば

$$
\left|r v_{z}\right|_{-h / 2}^{h / 2}=-\int_{-h / 2}^{h / 2} \frac{\partial}{\partial r}\left(r v_{r}\right) d z
$$

あるいは

$$
-\frac{r \dot{h}}{2}=\int_{0}^{-f r i(\dot{r} r)^{\prime}} \frac{\partial}{\partial r}\left(r v_{r}\right) d z+\int_{-f r /(p r)^{\prime}}^{h / 2} \frac{\partial}{\partial r}\left(r v_{r}\right) d z
$$

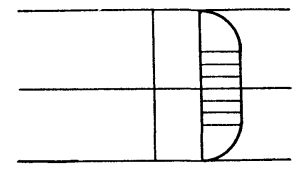

Fig. 3 Velocity profile 
さて $0 \leqq z \leqq-f r /(p r)^{\prime}$ では $v_{r}$ は一定で, $z=-f r /$ $(p r)^{\prime}$ における $v_{r}$ の值は

$$
\bar{v}_{r}=-\frac{f^{2} p^{\prime} r^{2}}{2 \eta\left\{(p r)^{\prime}\right\}^{2}}-\frac{f h}{2 \eta} \frac{p^{\prime} r}{(p r)^{\prime}}-\frac{h^{2}}{8 \eta} p^{\prime}
$$

に等しい。したがって(16)の右辺第 1 項は

$$
\begin{aligned}
& \int_{0}^{-f r /(r r) \prime} \frac{\partial}{\partial r}\left(r v_{r}\right) d z=-\frac{f r}{(p r)^{\prime}} \frac{\partial}{\partial r}\left(r \bar{v}_{r}\right) \\
& =\frac{f^{3}}{2 \eta} \frac{r}{(p r)^{\prime}} \frac{\partial}{\partial r} \frac{r^{3} p^{\prime}}{\left\{(p r)^{\prime}\right\}^{2}} \\
& +\frac{f^{2} h}{2 \eta} \frac{r}{(p r)^{\prime}} \frac{\partial}{\partial r} \frac{r^{2} p^{\prime}}{(p r)^{\prime}}+\frac{f h^{2}}{8 \eta} \frac{r}{(p r)^{\prime}} \frac{\partial}{\partial r}\left(p^{\prime} r\right)
\end{aligned}
$$

となる.つぎに(16)の右辺第 2 項に(14)を入れると

$$
\begin{aligned}
& \int_{-f r /(r p),}^{h / 2} \frac{\partial}{\partial r}\left(r v_{r}\right) d z \\
& =\frac{1}{2 \eta}\left[-\frac{h^{3}}{12}-\frac{f h^{2}}{4} \frac{r}{(p r)^{\prime}}+\frac{f^{3}}{3} \frac{r^{3}}{\left\{(p r)^{\prime}\right\}^{3}}\right] \frac{\partial}{\partial r}\left(p^{\prime} r\right) \\
& +\frac{f}{\eta}\left[-\frac{h^{2}}{8}-\frac{f h}{2} \frac{r}{(p r)^{\prime}}-\frac{f^{2}}{2} \frac{r^{2}}{\left\{(p r)^{\prime}\right\}^{2}}\right] \frac{\partial}{\partial r} \frac{p^{\prime} r^{2}}{(p r)^{\prime}}
\end{aligned}
$$

以上により(16)は結局つぎのううになる。

$$
\begin{aligned}
-\frac{r \dot{h}}{2} & =\frac{f^{3}}{6 \eta}\left[\frac{3 r}{(p r)^{\prime}} \frac{\partial}{\partial r} \frac{p^{\prime} r^{3}}{\left\{\left(p r^{\prime}\right)\right\}^{2}}+\frac{r^{3}}{\left\{(p r)^{\prime}\right\}^{3}} \frac{\partial}{\partial r}\left(p^{\prime} r\right)\right. \\
& \left.-\frac{3 r^{2}}{\left\{(p r)^{\prime}\right\}^{2}} \frac{\partial}{\partial r} \frac{p^{\prime} r^{2}}{(p r)^{\prime}}\right]-\frac{f h^{2}}{8 \eta} \frac{\partial}{\partial r} \frac{p^{\prime} r^{2}}{(p r)^{\prime}} \\
& -\frac{h^{3}}{24 \eta} \frac{\partial}{\partial r}\left(p^{\prime} r\right)
\end{aligned}
$$

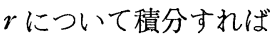

$$
-\frac{r^{2} \dot{h}}{4}+c=\frac{f^{3}}{6 \eta}-\frac{r^{4} p^{\prime}}{\left\{(p r)^{\prime}\right\}^{3}}-\frac{f h^{2}}{8 \eta} \frac{r^{2} p^{\prime}}{(p r)^{\prime}}-\frac{h^{3}}{24 \eta} r p^{\prime}
$$

$r \rightarrow 0$ とすれば $c=0$ であることがわかる．したがって $h^{3}\left\{(p r)^{\prime}\right\}^{3} p^{\prime}-6 \eta \dot{h} r\left\{(p r)^{\prime}\right\}^{3}$

$$
+3 f h^{2} r p^{\prime}\left\{(p r)^{\prime}\right\}^{2}-4 f^{3} r^{3} p^{\prime}=0
$$

あるいは

$$
\begin{aligned}
6 \eta r\left(p^{\prime} r+p\right)^{3} \dot{h} & =p^{\prime}\left\{h\left(p^{\prime} r+p\right)-f r\right\} \\
& \times\left\{h\left(p^{\prime} r+p\right)+2 f r\right\}
\end{aligned}
$$

$(p r)^{\prime}=\left(p^{\prime} r+p\right)$ であるが，いまかりに右辺第 2 項の $p$ を無視すれば(21)はS cottの導いた式

$$
g^{3}-g^{2}\left(\frac{3 f}{h}-\frac{6 \eta r}{h^{3}} \dot{h}\right)+\frac{4 f^{3}}{h^{3}}=0
$$

と一致する。ただし $g=-d p / d r$ である.

\section{4. $\boldsymbol{h}$ と $\boldsymbol{t}$ との関係}

ます(21)からpを求めるためにpを

$$
p=p_{0}+p_{1} \dot{h}+p_{2} \dot{h}^{2}+\cdots \cdots
$$

のようにhで展開して $(21)$ にれれば

$$
\begin{aligned}
& h^{3}\left\{\left(p_{0}^{\prime} r+p_{0}\right)+\left(p^{\prime}{ }_{1} r+p_{1}\right) \dot{h}+\cdots \cdots\right\}^{3} \\
& \times\left(p_{0}^{\prime}+p_{1}^{\prime} \dot{h}+p_{2}{ }^{\prime} \dot{h}^{2}+\cdots \cdots \cdot\right) \\
& -6 \eta \dot{h} r\left\{\left(p_{0}{ }^{\prime} r+p_{0}\right)+\left(p_{1}{ }^{\prime} r+p_{1}\right) \dot{h}+\cdots \cdots\right\}^{3} \\
& +3 f h^{2} r\left(p_{0}{ }^{\prime}+p_{1}{ }^{\prime} \dot{h}+p^{\prime}{ }_{2} \dot{h}^{2}+\cdots \cdots\right) \\
& \times\left\{\left(p_{0}{ }^{\prime} r+p_{0}\right)+\left(p_{1}{ }^{\prime} r+p_{1}\right) \dot{h}+\cdots \cdots\right\}^{2} \\
& -4 f^{3} r^{3}\left(p_{0}{ }^{\prime}+p_{1}{ }^{\prime} \dot{h}+p_{2}{ }^{\prime} \dot{h}^{2}+\cdots \cdots\right)=0
\end{aligned}
$$

$\dot{h}$ の零次の係数を零とおけば

$$
h^{3}\left(p_{0}{ }^{\prime} r+p_{0}\right)^{3} p_{0}{ }^{\prime}+3 f h^{2} r p_{0}{ }^{\prime}\left(p_{0}{ }^{\prime} r+p_{0}\right)^{2}-4 f^{3} r^{3} p_{0}{ }^{\prime}=0
$$

あるいは

$$
p_{0}^{\prime}\left\{h\left(p_{0}^{\prime} r+p_{0}\right)-f r\right\}\left\{h\left(p_{0}^{\prime} r+p_{0}\right)+2 f r\right\}^{2}=0
$$

これから

$$
p_{0}=f r / 2 h
$$

または

$$
p_{0}=-f r / h
$$

つぎに(25)で 1 次の係数を零とおけば $p_{1}$ が求められ る. $(26 \mathrm{a}),(26 \mathrm{~b})$ に対応して

$$
\begin{aligned}
& p_{1}=3 \eta r^{2} / h^{3}+c \\
& p_{1}=-3 \eta r^{2} / 5 h^{3}+c
\end{aligned}
$$

ゆえに圧力 $p$ は

$$
p=\frac{f r}{2 h}-\frac{3 \eta r^{2}}{5 h^{3}} \dot{h}+c \dot{h}
$$

あるいは

$$
p=-\frac{f r}{h}+\frac{3 \eta r^{2}}{h^{3}} \dot{h}+c \dot{h}
$$

$f=0$ とした場合に $p$ はニュートン液体に対するもの に一致しなければならないから，(28a)をすて $(28 \mathrm{~b})$ をとる。

平行板に働く荷重を $F$ とすると, 力のつりあいの式 は

$$
\int_{0}^{R} p \cdot 2 \pi r \cdot d r=F+\pi R^{2} p_{0}
$$

となる.ここにRは試料の半径である． $p_{0}$ は大気圧で $(28 \mathrm{~b})$ において $r=R$ とおいて得られる。（28b）を (29)に代入して，

$$
F=-\frac{3 \pi \eta R^{4}}{2 h^{3}} \dot{h}+\frac{f \pi R^{3}}{3 h}
$$

ここで試料が平行板からはみ出している場合 (I )と平 行板の間にある場合 (II) とを分けて考える.

(I ) $R=a$ の場合

ここに $a$ は円板の半径である. (30)を書き直すとつ ぎようになる。

いま

$$
-\dot{h}=\frac{2 h^{3}}{3 \alpha \eta a^{4}}\left(F-\frac{f \pi a^{3}}{3 h}\right)
$$

$$
h_{l}=\frac{\pi a^{3} f}{3 F}
$$

とおけば， $h \rightarrow h_{l}$ のとき $-\dot{h} \rightarrow 0$ となる。したがって， $\dot{h}=0$ となる $h_{l}$ から降伏值 $f$ が求められる。 また $(31)$ から

$$
\log \left(-\frac{\dot{h}}{h^{3}}\right)=\log \left(F-\frac{\pi a^{3} f}{3 h}\right)+\log \left(\frac{2}{3 \pi a^{4} \eta}\right)
$$

したがって $\log \left(-\dot{h} / h^{3}\right)$ を $\log \left(F-\pi a^{8} f / 3 h\right)$ に対し てプロットし，その直線が縦軸を切る長さからクが求 まる.とくに $\pi a^{3} f / 3 h F \ll 1$ として，(31)をhについ て $h_{0}$ から $h$ まで積分すれば次式が得られる. 


$$
\frac{3 \pi a^{4}}{4}\left(\frac{1}{h^{2}}-\frac{1}{h_{0}^{2}}\right)+\frac{f \pi^{2} a^{7}}{6 F}\left(\frac{1}{h^{3}}-\frac{1}{h_{0}^{3}}\right)=\frac{F}{\eta} t
$$

ここで $f=0$ とおけばニュートン液体の場合にStefan により導かれた式

$$
\frac{3 \pi a^{4}}{4}\left(\frac{1}{h^{2}}-\frac{1}{h_{0}^{2}}\right)=\frac{F}{\eta} t
$$

と完全に一致する.

(II) $\pi R^{2} h=V=$ 一定の場合

(30)はつぎのように書き直される。

$$
F=\frac{3 \eta V^{2}}{2 \pi h^{5}} \dot{h}+\frac{f V^{3 / 2}}{3 \pi^{1 / 2} h^{5 / 2}}
$$

あるいは

いま

$$
-\dot{h}=\left(F-\frac{f V^{3 / 2}}{3 \pi^{1 / 2} h^{5 / 2}}\right) \frac{2 \pi h^{5}}{3 \eta V^{2}}
$$

$$
h_{l}=\left(\frac{V^{3 / 2} f}{3 \pi^{1 / 2} F}\right)^{2 / 5}
$$

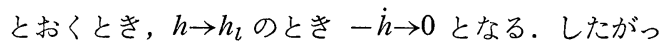
て, $h=0$ となる $h_{l}$ から降伏值 $f$ が求められる. また (37)から

$$
\log \left(-\frac{\dot{h}}{h^{5}}\right)=\log \left(F-\frac{f V^{3 / 2}}{3 \sqrt{\pi} h^{5 / 2}}\right)+\log \left(\frac{2 \pi}{3 \eta V^{2}}\right)
$$

$\log \left(-\dot{h} / h^{5}\right)$ を $\log \left(F-\frac{f V^{3 / 2}}{3 \sqrt{\pi} h^{5 / 2}}\right)$ に対してプロ ットし，直線が縱軸を切る長さからクが求められる。

いま $f V^{3 / 2} / 3 \sqrt{\pi} F h^{5 / 2} \ll 1$ と仮定して, (37)を $h$ について $h_{0}$ から $h$ まで積分すれば次式が得られる.

$$
\frac{3 V^{2}}{8 \pi}\left(\frac{1}{h^{4}}-\frac{1}{h_{0}^{4}}\right)+\frac{f V^{7 / 2}}{13 F \pi^{3 / 2}}\left(\frac{1}{h^{13 / 2}}-\frac{1}{h_{0}^{13 / 2}}\right)=\frac{F}{\eta} t
$$

ここで $f=0$ とおけばニュートン液体に対して Healey により導かれた式

$$
\frac{3 V^{2}}{8 \pi}\left(\frac{1}{h^{4}}-\frac{1}{h_{0}^{4}}\right)=\frac{F}{\eta} t
$$

と完全に一致する.

\section{参考 文 献}

1) J. Stefan, Sitzungsber, Acad. Wiss. Wien, 69, 713 (1874), J.J. Bikerman, J, Colloid Sci., 29, 163 (1947) 参照

2) Healey, Trans. Inst. Rubber Ind., 1, 334 (1925)

3) G.J. Dienes and H.F. Klemm, J. Appl. Phys., 17, 458 (1946)

4) J.R. Scott, Trans. Inst. Rubber Ind., 7, 169 (1931), 10, $481(1934 / 35)$

\section{樹脂とカラスの接着特性について (Resin-Glass} Bond Characteristics) by F.J. McGarry, Bulletin ASTM, No. 235 (Jan. 1959), (TP 33 38) pp. 63〜 68 , 図 10, 表なし, 文献 4

強化プラスチックスの補強材ガラス繊維と重合性三 次元網状樹脂の接着特性力に関する基礎的研究として, ガラス棒あるいはモノフィラメントを樹脂中に注型し て接着強度試験を行なっている. 実験法は (1) Pyrex ガラス棒をいろいろの厚さの円盤状樹脂の中央を貫い て注型とした試験片につき圧縮により接着力を測定す る.（2）同様な試験片をねじりにより接着力を測定す る.（3)二次元くさび状樹脂の中央にガラス繊維モ） フィラメントを注型した試験片を压縮すると, 各断面 で異なる種々の応力を受けたときの樹脂とモノフィラ メントとの相互接着力の関係が一度に観察できる。が ラスの表面処理ガラス棒の直径, 樹脂円艋の厚さ, 樹脂
の種類を変えて試験片を造り, 流体圧式試験機て荷重 一変位曲線を画かせた。得られた結果はポリエステル 樹脂の場合はガラスにおけるいろいろな表面処理の影 響がほとんと認められず，破壊は常に両者の界面で発 生し, ガラス表面をあらくして摩擦を增さないかぎり 相互の接着強度はそれぞれの強度よりはるかに低く破 断面も美麗である。これはガラス表面の污変，ポリエ ステル樹脂の局部的劣化あるいは不完全キュアーによ るものだろうとしている.ポリエステル樹脂ガラス系 の場合はキュアーにおける樹脂の収縮, 両者の熱膨張 係数の相違なとによる摩擦の增大はきわめて大切であ る.これに対してェポキシ樹脂一ガラス系の破壊は相 互の中間界面では決して起らず，相互の接着力は両者 の真の結合力凝結力に近くなっていて, 二成分の実質 的融合を物語っている.

(伊藤勝楌) 